\title{
DINÂMICA POPULACIONAL E DESENVOLVIMENTO TERRITORIAL NA REGIÃO FUMAGEIRA ALAGOANA: EVIDÊNCIAS PARA ARAPIRACA, ALAGOAS
}

Maria Isabel Souza ${ }^{1}$ Keuler Hissa Teixeira ${ }^{2}$

Resumo: O presente trabalho tem como objetivo entender como a cultura fumageira alterou a dinâmica populacional e os rumos do desenvolvimento territorial do agreste alagoano, mais precisamente do município de Arapiraca, centro de confluência da dinâmica regional e urbana desta região. Para lograr tal fim, a metodologia adotada constituiu-se de uma análise tabular descritiva de dados que foram obtidos a partir do Instituto de Pesquisa Econômica Aplicada - IPEA e dos censos agropecuários do IBGE, além da revisão de literatura específica ao tema em questão. Dito isso, constatou-se que houve uma concentração regional de serviços no município de Arapiraca e, consequentemente, uma maior aglomeração populacional, fruto dos movimentos migratórios para as áreas urbanas do referido município.

Palavras-chave: Dinâmica urbana; Cultura fumageira; Arapiraca

\section{POPULATION DYNAMICS AND TERRITORIAL DEVELOPMENT IN THE ALAGOANA SMOKING REGION: EVIDENCE FOR ARAPIRACA, ALAGOAS}

Abstract: The present paper aims to understand how the culture fumageira changed the population dynamics and the directions of the territorial development of the Alagoan agreste, more precisely of the municipality of Arapiraca, center of confluence of the regional and urban dynamics of this region. To achieve this aim, the methodology adopted was a tabular descriptive analysis of data that were obtained from the Institute of Applied Economic Research - IPEA and IBGE's agricultural censuses, in addition to the literature review specific to the subject in question. That said, it was found that there was a regional concentration of services in the city of Arapiraca and, consequently, a greater population agglomeration, fruit of the migratory movements to the urban areas of the mentioned municipality.

Keywords: Urban dynamics; Culture fumageira; Arapiraca

\section{DINÁMICA POBLACIONAL Y DESARROLLO TERRITORIAL EN LA REGIÓN FUMAGEIRA ALAGOANA: EVIDENCIAS PARA ARAPIRACA, ALAGOAS}

Resumen: El trabajo tiene pretende entender cómo la cultura fuumbrera alteró la dinámica poblacional y los rumbos del desarrollo territorial del agreste alagoano, más precisamente del municipio de Arapiraca, centro de confluencia de la dinámica regional y urbana de esta región. La metodología adoptada se constituyó de un análisis tabular descriptivo de datos que fueron obtenidos a partir del Instituto de Investigación Económica Aplicada - IPEA y de los censos agropecuarios del IBGE, además de la revisión de literatura específica al tema en cuestión. Dicho esto, se

\footnotetext{
1 Universidade Federal de Pernambuco (UFPE), Programa de Pós-Graduação em Economia (PPGECON), Caruaru (PE), Brasil, bebelsouza07@hotmail.com, https://orcid.org/0000-0003-0956$477 X$.

2 Universidade Federal de Alagoas (UFAL), Faculdade de Economia, Administração e Contabilidade (FEAC), Maceió (AL), Brasil, keulerhissa@hotmail.com, https://orcid.org/0000-0002-8385-9480.
} 
constató que hubo una concentración regional de servicios en el municipio de Arapiraca y, consecuentemente, una mayor aglomeración poblacional, fruto de los movimientos migratorios hacia las áreas urbanas del referido municipio.

Palabras clave: Dinámica urbana; Cultura fumagica; Arapiraca

\section{Introdução}

A produção do fumo no Nordeste brasileiro surgiu junto à vinda da população escrava as fazendas de café, tornando-se um produto cultivado desde o Brasil colônia. Contudo, o mesmo não figurava um bem comercializável como a cana-de-açúcar naquela época, e supria apenas o consumo próprio das famílias. No estado de Alagoas, especificamente, a produção fumageira ganhou notoriedade no Agreste da região, sendo cultivado em consórcio com outras culturas como feijão e mandioca. O fumo cresceu baseado na agricultura familiar e dentro de pequenas propriedades, o que lhe conferiu uma maior dinâmica social, pois grande parte da população usufruía de sua valorização comercial. O município de Arapiraca, situado no meio do estado alagoano, tornou-se o centro dinâmico desta cultura e, por isso, grande usufruto da dinâmica social e econômica inerente ao desenvolvimento do mesmo.

O agreste alagoano, cercado por uma área de influência canavieira ao leste e pecuarista ao oeste, apresentou um desenvolvimento territorial totalmente distinto do seu entorno, baseada em um cultivo que Ihe permitia um desenvolvimento mais igualitário, já que até as camadas mais pobres poderiam cultivar a folha de fumo sem grandes esforços financeiros e territoriais. A influência de determinados cultivos e suas características de plantio e mercadológicas podem afetar de forma variada a dinâmica demográfica de uma região. Dito isso, o objetivo do presente trabalho é analisar como a produção fumageira alagoana afetou o desenvolvimento territorial do Agreste do estado desde o princípio de sua produção comercial, em 1890 até o ano de 2010, e de que forma essa nova dinâmica demográfica se manifestou, de maneira específica, no município de Arapiraca, centro comercial dessa produção.

Por isso, além da revisão de literatura acerca do tema, o trabalho recorreu a uma análise tabular descritiva de dados que foram obtidos a partir do Instituto de Pesquisa Econômica Aplicada - IPEA e dos censos agropecuários do IBGE (1970,1975 e 1980). Para tanto, a pesquisa se dividiu em quatro subgrupos, sendo o primeiro uma introdução à mesma, o segundo traz a formação territorial do agreste alagoano desde o Brasil colônia, o terceiro trata do surgimento da dinâmica 
fumageira na região e suas consequências territoriais, sociais e econômicas, e o quarto traz as conclusões acerca do estudo.

\section{A formação do território do Agreste Alagoano}

Pensar na formação de um território é avaliar momentos históricos distintos em que diferentes agentes sociais estabelecem usos dissemelhantes aquele local. Este processo de formação é de primordial relevância para as características sociais, econômicas e políticas futuras daquela região, desta forma, o estudo da constituição territorial do Agreste alagoano trará luz as particularidades desta localidade, que é de elementar importância para este estudo.

Partindo do princípio de que, para entender o contexto local do Agreste alagoano, é necessário entender o processo de formação e os primeiros usos do território como um todo, faz-se necessário retomar a fatos históricos que basearam o desenvolvimento de culturas distintas.

O território que hoje pertence ao estado alagoano já foi região sul da capitania de Pernambuco, principal área de plantio da cana-de-açúcar desde os primeiros anos de colonização. Independente em 17 de setembro de 1817, Alagoas tornou-se província e teve sua ocupação territorial inicial atrelada ao avanço da cultura canavieira. Baseado no latifúndio e na mão-de-obra escrava, para o desenvolvimento desta cultura era apenas necessário a ocupação de novas terras. Os grandes proprietários de engenho eram os únicos beneficiados por essa expansão, pois se apropriavam do capital excedente fruto desse desenvolvimento, capital este que não era direcionado para a economia da região, mas para o mercado internacional. Para Celso Furtado (2000) esse capital excedente quando não consumido na localidade, não gera fluxo de renda monetária e consequentemente, não impulsiona a economia local, apenas beneficiando a quem se apropriou do mesmo. Furtado afirma, (2000, pag. 47) "Se o excedente está na base de tudo que despende uma sociedade fora da satisfação de suas necessidades essenciais, o problema de como medi-lo limita-se a definição das referidas necessidades." Quando o excedente é direcionado a ascensão para padrões de consumo cada vez mais elevados, sem qualquer benefício na evolução social local, o subdesenvolvimento começa a tomar forma nesta economia.

Dito isso, a economia canavieira alagoana estava fadada a intensa estratificação social, concentração de renda, baixo dinamismo econômico, entre outros problemas, mais presente em municípios onde esta cultura foi predominante, 
como em Maceió, Coruripe, Rio Largo, e São Miguel dos Campos, a maioria situados no leste do estado, que tinha como facilidade o escoamento da produção pelos portos marítimos.

Induzidos pela economia açucareira surgem diversos fenômenos econômicos adjacentes, o principal deles foi a pecuária. Para atender a demanda de força motriz, a atividade criatória exigia uma crescente expansão de terras, como o litoral alagoano já estava ocupado pela agricultura canavieira, restou a pecuária ocupar as regiões mais ao oeste. Reafirmando a característica latifundiária já utilizada no cultivo da cana, a pecuária tinha seus rendimentos cada vez mais prejudicados com a incorporação de terras cada vez mais improdutivas, devido ao afastamento do litoral, tornando os criadores mais distantes marginalizados. Somando-se a característica de subsistência inerente a essa produção gerou-se nesta economia um baixo rendimento monetário e um aumento da economia de subsistência. Contudo, a pequena expressão de seus custos deixava a mesma muito mais resistente às flutuações de preço, e consequentemente, de lucro advindas do cultivo da cana.

Além da pecuária, a cultura canavieira também demandou determinada produção alimentícia para abastecer os engenhos. Como o território litorâneo já estava ocupado com a produção de cana-de-açúcar e a mesma não admitia consórcio com outras culturas, o cultivo de alimentos como o milho, mandioca, feijão, dentre outros produtos ficou para regiões um pouco mais afastadas do litoral, no Agreste alagoano. De acordo com Sales, (1982, p.40 apud Teodoro, 2014, p.62):

“... existe o agreste pecuário, especializado na criação de gado bovino, sendo predominante, e o outro Agreste, provavelmente o mais restrito em termos de composição espacial, é aquele que se especializa na produção alimentar para o mercado baseada, sobretudo, nos cultivos de hortifruticultura e na vinicultura."

Historicamente, situado entre a Zona da Mata e o Sertão, o Agreste é caracterizado como zona de transição, no caso alagoano, do leste latifundiário e canavieiro e o oeste pecuarista. Segundo o Plano Territorial de Desenvolvimento Rural Sustentável do Agreste de Alagoas (2011), ocupando uma área de 5.271 km², esta região mostra sua identidade territorial através da sua história, como polo de abastecimento alimentício do leste canavieiro; da estrutura fundiária semelhante, com a predominância da pequena e média propriedade; através da economia baseada na cultura de subsistência, com a produção de milho, feijão, mandioca e 
batata doce; pelo tipo de agricultura de mercado, com o fumo e o algodão; e pela estrutura fisiográfica semelhante.

O vale do rio São Francisco foi de grande importância para o povoamento inicial do Agreste e do Sertão alagoano, mas alguns fatos se mostraram decisivos para o desbravamento efetivo daquela região. O primeiro deles, data do final do século XVII, que foi a destruição do Quilombo dos Palmares, dando margem ao surgimento de inúmeras sesmarias longe do domínio português. A luta dos índios Cariris contra os pecuaristas da região pelo domínio da terra também ajudou a desbravar o agreste e parte do sertão alagoano, surgindo, então as primeiras grandes fazendas agrestinas.

De acordo com ANDRADE (1963, p.6-7)

Entre uma área outra firma-se uma zona de transição, com trechos quase tão úmidos como a Mata e outros tão secos como o Sertão, alterando-se constantemente e a pequena distância, que o povo chamou de Agreste. Daí, dessa diversidade climática, surgiria a dualidade consagrada pelos nordestinos e expressa no período colonial em dois sistemas de exploração agrária diversos, que se complementam economicamente mas que, política e socialmente se contrapõem: o Nordeste da cana-de-açúcar e o Nordeste do gado, observando entre um e outro, hoje, o Nordeste da pequena propriedade e da policultura.'

Segundo Teodoro (2014), diferente da zona da mata e do sertão, a ocupação territorial do agreste foi baseada em pequenas e médias propriedades, se constituindo, basicamente pela trilogia pecuária, algodão e policultura de subsistência, por bases tradicionais do uso da terra e pela presença do produtor familiar. A nascente população do Agreste alagoano era pobre, criava gado em propriedades e quantidades menores do que as do Sertão cultivava milho, feijão, mandioca e cana-de-açúcar para a produção de rapadura e mel em lavouras de pequena escala e, consequentemente, lucros reduzidos. Mas, foi a cotonicultura que integrou o Agreste de forma direta ao mercado externo.

Diferentemente, da cana, o algodão permitia o plantio em consórcio com outras culturas, como o feijão e o milho, podendo ser realizado por pequenos e médios proprietários de terras, pois, também não exigia altos níveis de capital investidos, como consequência, a dinamização proporcionada por este cultivo foi muito superior a usufruída pela cana-de-açúcar. A cultura algodoeira foi de extrema relevância para a formação dos primeiros centros urbanos no sertão. Segundo Guimarães Neto (1989, p.31 apud Ferrario, 2001, p.16) " o algodão, estimulado pelo surto exportador trouxe repercussões significativas sobre a economia da região, com 
os desdobramentos sobre a atividade produtiva interna, sobretudo a atividade de transformação e o comércio interno"

Durante a primeira estagnação da produção açucareira, por volta de 1750, o algodão passou a protagonista no cenário nordestino, responsável por realocar todo excedente de mão-de-obra da indústria canavieira para o seu cultivo, favorecendo, desta forma, o aumento populacional do Agreste. Assim, como seu investimento inicial, a cultura algodoeira requeria uma industrialização muito mais barata quando comparado ao da cana-de-açúcar, sendo de mais fácil realização pelos pequenos produtores. Mais tarde, mas, precisamente, na metade no século XIX, a produção de algodão alagoana já contava com empresas atuantes no processo de beneficiamento, todas instaladas no município de Arapiraca, no Agreste alagoano, foram elas a Bagense S.A Indústria, Comércio e Agricultura; Algodoeira Arapiraca S.A; e Algodoeira São Francisco.

Já em meados do século XVII, o surto algodoeiro atingia os pequenos e grandes produtores do estado, permitindo que muitos deles participassem da vida política e administrativa de Alagoas. Essa cultura proporcionou o melhoramento das condições econômicas e sociais de muitos pequenos produtores, já que a estrutura fundiária deste cultivo era voltada para as pequenas e médias propriedades. Para Furtado (2000), o tipo de estrutura agrária é condicionado por um misto de escassez ou abundância de terras aliadas à facilidade ou dificuldade de acesso as mesmas, no caso algodoeiro havia uma abundância e facilidade de acesso as mesmas. No entanto, o protagonismo algodoeiro no cenário internacional ficou restrito a períodos de crise enfrentados por outros núcleos produtivos, como por exemplo, a guerra de secessão nos Estados Unidos, que passou a comprar o algodão brasileiro ao inglês. A cultura, mais tarde, enfrentou seu declínio efetivo marcado pela expansão do algodão paulista e pela praga da lagarta rosada. Ainda assim, a cultura algodoeira, foi por volta de um século e meio, a principal base produtiva e econômica do Agreste alagoano (TEODORO, 2014).

Já no fim do século XIX, inicia-se o cultivo do fumo, produto este que, futuramente, tornaria o Agreste alagoano, mas, precisamente, a cidade de Arapiraca, referência nacional nessa atividade. Tem começo a mais importante fase da estrutura produtiva, social, e econômica dessa região, responsável por promover a efetiva reestruturação da mesma. 


\section{Dinâmica da produção fumageira e restruturação do território}

O cultivo do fumo em território alagoano iniciou-se em 1890, no município de Arapiraca, segundo alguns autores, por livre iniciativa de produtores locais insatisfeitos com a agricultura de subsistência baseada principalmente na cultura da mandioca. Inicialmente, cultivado em currais, o fumo arapiraquense ganhou o nome de "fumo de curral" em sua fase pré-técnica. Associado à agricultura familiar de subsistência, não demorou muito para o mesmo espalhar-se pelo Agreste.

A feira livre de Arapiraca também merece destaque, criada em 1884, ganha rápido crescimento pelo fato do município em questão ser área de passagem de trabalhadores entre o Sertão e a Zona da Mata, e por isso, referência na compra de suprimentos. Acompanhando o crescimento da produção agrícola e das atividades comerciais, a feira atraía comerciantes e consumidores de diversas localidades, chegando a ganhar o título, em 1960, de uma das maiores feiras livres do Nordeste.

Segundo Teodoro (2014), denominamos de Região Fumageira de Alagoas a porção regional formada pelo agrupamento dos municípios de Arapiraca, Craíbas, Coité do Noiá, Campo Grande, Feira Grande, Giral do Ponciano, Lagoa da Canoa, Limoeiro de Anadia, São Sebastião e Taquarana, tomando como principal referência a concentração da produção do tabaco alagoano na área de influência do município de Arapiraca, como demonstrado na Figura 1. 
Figura 1. Região fumageira de Alagoas no agreste do Estado

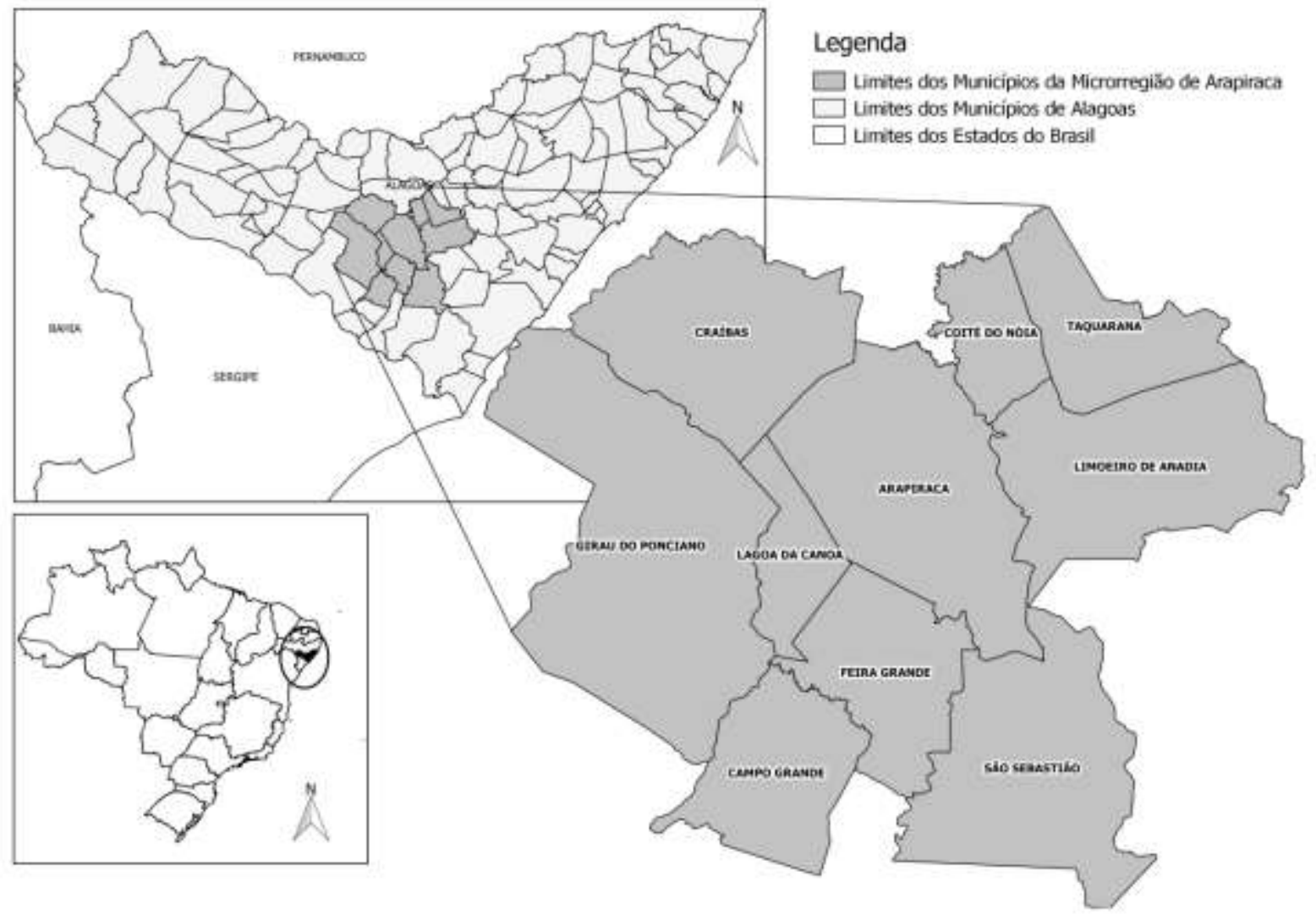

Fonte: Elaboração própria dos autores.

A predominância produtiva do fumo homogeneíza estes municípios, todos localizados no centro do estado alagoano e sofrendo fortes influências do principal produtor, Arapiraca. Para Araújo (2009), porém, os mesmos apresentam diversas diferenciações culturais, sociais e econômicas. Destacando o feijão, o algodão, o milho, e a mandioca, como principais produtos cultivados paralelamente ao fumo nesta região, como analisado na Tabela 1.

Tabela 1. Produção (toneladas) e área (hectares) das principais culturas plantadas na região fumageira de Alagoas nos anos de 1973, 1974 e 1979.

\begin{tabular}{|c|c|c|c|c|c|c|}
\hline \multirow{2}{*}{ Principais Culturas } & \multicolumn{2}{|c|}{1973} & \multicolumn{2}{|c|}{1974} & \multicolumn{2}{|c|}{1979} \\
\hline & Área & Produção & Área & Produção & Área & Produção \\
\hline Fumo & 23.325 & 21.42 & 26.856 & 24.774 & 34.233 & 30.976 \\
\hline Algodão & 17.565 & 4.375 & 23.157 & 5.623 & 26.74 & 5.064 \\
\hline Milho & 13.1 & 7.049 & 13.284 & 7.075 & 15.181 & 8.187 \\
\hline Mandioca & 9.037 & 92.5 & 8.855 & 88.55 & 9.049 & 90.486 \\
\hline Feijão & 9.67 & 4.653 & 20.098 & 9.586 & 15.329 & 9.882 \\
\hline
\end{tabular}

Fonte: Elaboração própria a partir dos dados do IPEADATA (2018).

Os primeiros passos para a ascensão da cultura fumageira nesta região ocorreram em 1930. A partir da introdução do sistema "meeiro" na produção do 
"fumo Arapiraca", a terra passou a ser arrendada e a produção dividida entre o dono do estabelecimento e o agricultor, incentivando famílias sem terras a também participarem da produção e, consequentemente, usufruir do lucro do mesmo, mas foi apenas nos 70 que se apresentou um bom desempenho em escala produtiva do fumo. Para Furtado (2000), o acesso a terra é de elementar importância para a formação de renda em uma economia, dada este acesso às famílias, elas são capazes de gerar renda e consumir produtos, além de participarem e usufruírem do desenvolvimento econômico e social da sua região de maneira mais uniforme.

Quanto à mão-de-obra, o fumo, por ser uma lavoura que exigia um maior cuidado em todo processo produtivo, destacou-se por pagar melhores salários ao trabalhador rural quando comparado a outras lavouras, exigindo grande contingente de mão-de-obra, essa característica gerou um movimento migratório temporário proveniente da zona da mata açucareira nos períodos da entressafra.

Segundo Teodoro (2014), apenas em 1945 iniciou-se a ascensão urbana e econômica do município de Arapiraca no contexto regional, com a vinda da primeira fábrica de charutos, a "Fábrica de Charuto Leda", que se instalou no município. Em 1950, com a produção elevada de folhas para esse comércio, se instala em Arapiraca a primeira firma multifuncional, chamada Exportadora Garrido, inaugurando a internacionalização do setor fumageiro alagoano, após isso, sucessivas firmas internacionais se instalaram. De acordo com Oliveira (2007), a partir de 1951 chegaram várias empresas a região, foram elas; Pimentel, Carl Leoni, Bert Evert Beckovich, e a Fumex. Depois, em 1956 as empresas Sverdieck, Monjeru, Ermor, dentre outras, se estabeleceram.

Segundo Oliveira (2007), a compra do fumo em folha arapiraquense era dominada por três empresas, eram elas: Danco Comércio e Indústria, Ermo Tabarana Tabacos do Brasil, e Fumex Tabacalera LTDA. Enquanto, as empresas locais dominavam o comércio do fumo em corda, foram elas: Icasil, Incofusbom, e Coringa.

A grande maioria destas multinacionais instalou-se no município de Arapiraca, pois a região continha a maior área cultivada de fumo com tendência a expansão, maior facilidade de escoamento da produção, acesso a serviços de infraestrutura urbana, crescimento urbano e mão-de-obra acessível.

Em 1960, Arapiraca ganha a referência de maior parque fumageiro da América Latina em área contínua. Passando por um período de auge econômico, o município registra uma das melhores rendas per capta, em termos das regiões Norte 
e Nordeste, daquele ano. Para Souza (2009), a dinâmica econômica do município já era elevada naquela época, e contava com diversificada oferta de produtos e serviços, quando comparado aos demais municípios da sua região, abrangendo postos de gasolina, supermercados, serviços bancários, entre outros. Todos impulsionados pela produção fumageira e sua socialização de lucros fruto do acesso dos pequenos e médios produtores a terra e, consequentemente, sua produção e posterior obtenção de renda.

Em 1963, ocorre uma mudança na política fiscal do estado, tornando mais vantajoso a exportação do fumo alagoano através do porto de Maceió, que agora não precisava mais enviar sua produção para o estado baiano, também grande produtor de fumo. Fato este que, juntamente, com a reforma tributária de 1966, que encareceu o custo da expedição do fumo alagoano para a Bahia promoveu maior autonomia ao Estado de Alagoas quanto a sua produção, impulsionando ainda mais a economia fumageira local.

Nos anos 70, Arapiraca já apresentava a maior densidade populacional e urbana do Agreste, despontando como município mais desenvolvido daquela região. Naquele ano, a população absoluta de Arapiraca era 94.287, representando aproximadamente $6 \%$ da população total do Estado de Alagoas e cerca de $49,1 \%$ de toda a população da região fumageira, conforme dados do Ipea (2018).

Como dito anteriormente, a cultura fumageira é caracterizada pelo plantio em pequenas e médias propriedades e pela agricultura familiar, típico do agreste alagoano. Sendo esta cultura a responsável pela ocupação de maior extensão territorial, o número de estabelecimentos por estrato de área na região fumageira define o tamanho médio das propriedades agrícolas nos períodos de desenvolvimento, conforme analisado na Tabela 2.

Tabela 2. Número de estabelecimentos agrícolas por estrato de área na região fumageira de Alagoas - 1970, 1975 e 1980.

\begin{tabular}{|c|c|c|c|}
\hline \multirow{2}{*}{$\begin{array}{c}\text { Estrato de } \\
\text { Área }\end{array}$} & \multicolumn{3}{|c|}{ Número de Estabelecimentos } \\
\hline & 1970 & 1975 & 1980 \\
\hline 0 ha - 2 há & 4.079 & 6.309 & 10.623 \\
\hline 2 há - 10 há & 7.981 & 7.376 & 7.148 \\
\hline 10 há - 20 há & 1.907 & 1.620 & 1.481 \\
\hline 20 há - 50 há & 1.297 & 1.122 & 1.082 \\
\hline 50 há - 100 há & 371 & 324 & 394 \\
\hline 100 há - 500 há & 211 & 222 & 242 \\
\hline 500 há - 2000há & 28 & 30 & 25 \\
\hline + 2000 há & 1 & 3 & 2 \\
\hline
\end{tabular}

Fonte: Elaboração própria a partir dos censos agropecuários do IBGE (1970,1975 e 1980). 
Pode-se concluir que existe um aumento na formação de propriedades de 0 a 2 hectares de terra, entre 1970 e 1980 na região fumageira. Em 1980, mais de $50 \%$ dos estabelecimentos agrícolas tinham até dois hectares, e existiam apenas 25 com área entre 500 e 2000 hectares em todos os dez municípios da região. Nota-se também uma clara evolução entre no período analisado das pequenas propriedades, neste sentido, Gusmão afirma (1985, apud Teodoro, 2014, p.111)

Historicamente, a organização fundiária do município de Arapiraca se baseou nas pequenas propriedades. Assim, a agricultura familiar se fez significativa onde os arrendamentos das propriedades podiam ser pagos em forma de produto ou dinheiro, fatores que contribuíam com o desenvolvimento do fumo no município.

Segundo Oliveira (2007), os micros e pequenos produtores que ocupavam estas terras, constantemente, deparavam-se com a figura do atravessador, presença comum em períodos pré-capitalistas, e há décadas presente na cultura fumageira, até a vinda das primeiras grandes empresas a região. Alterando as relações produtivas, o sistema de parceria entre o produtor e a empresa era realizado na forma de contrato, que segundo este mesmo autor, é uma forma de proletarização disfarçada do camponês. Esta modernização nas relações produtivas acabou congregando parcelas produtivas da agricultura familiar.

As novas relações de trabalho não permitiam vínculo direto com a terra após a colheita. Maiorias dos agricultores deixaram de ser meeiros para se tornarem boias frias, e viver na periferia de Arapiraca, deixando-os totalmente dependentes das multinacionais e do seu processo de desenvolvimento capitalista. Para Furtado (2000, pag. 28) "As massas demográficas, que a modificação das formas de produção priva de suas ocupações tradicionais, buscam abrigo em sistemas subculturais urbanos que só esporadicamente se articulam com os mercados, mas sobre ele exercem uma forte influência como reservatórios de mão-de-obra". Muitas famílias provenientes da zona rural migraram para a cidade em busca de emprego nestas empresas, este movimento é evidenciado pelo aumento da população urbana a partir de 1960, segundo Tabela 3. 
Tabela 3. Evolução da população urbana e rural da região fumageira de Alagoas entre 1960 a 2000.

\begin{tabular}{lccccccccccc}
\hline \multirow{2}{*}{ Município } & \multicolumn{2}{c}{1960} & \multicolumn{2}{c}{1970} & \multicolumn{2}{c}{1980} & \multicolumn{2}{c}{1991} & \multicolumn{2}{c}{2000} \\
\cline { 2 - 11 } & Urbano & Rural & Urbano & Rural & Urbano & Rural & Urbano & Rural & Urbano & Rural \\
\hline Arapiraca & 18.998 & 37.659 & 46.592 & 47.695 & 87.211 & 48.967 & 130.963 & 33.958 & 152.354 & 34.112 \\
Campo Grande & 1.379 & 2.731 & 1.43 & 5.99 & 2.74 & 6.553 & 4.004 & 6.037 & 3.703 & 5.431 \\
Coité do Nóia & - & - & 676 & 6.371 & 1.229 & 7.734 & 2.081 & 7.718 & 2.519 & 9.474 \\
Craíbas & - & - & - & - & - & - & 5.068 & 12.748 & 6.608 & 14.181 \\
Feira Grande & 4.243 & 8.428 & 1.707 & 11.603 & 1.878 & 15.664 & 2.813 & 16.239 & 3.557 & 17.713 \\
Girau do Ponciano & 3.727 & 7.389 & 1.543 & 16.804 & 3.596 & 18.863 & 7.553 & 20.248 & 8.858 & 20.716 \\
Lagoa da Canoa & - & - & 1.186 & 10.376 & 2.974 & 9.62 & 4.909 & 10.991 & 8.886 & 11.102 \\
Limoeiro de Anadia & 9.585 & 18.979 & 1.018 & 15.707 & 1.151 & 17.022 & 1.528 & 17.919 & 2.105 & 22.158 \\
São Sebastião & 1.93 & 3.823 & 764 & 10.959 & 2.326 & 17.438 & 7.35 & 17.346 & 9.408 & 19.716 \\
Taquarana & - & - & 1.038 & 10.723 & 2.318 & 10.871 & 3.491 & 13.318 & 4.371 & 12.675 \\
\hline
\end{tabular}

Fonte: Elaboração própria a partir dos dados do IPEADATA (2018).

Entre os anos de 1960 e 1970 a população urbana de Arapiraca cresceu $145 \%$. Após esta explosão, o município seguiu com boas taxas, chegando a registrar em 2010 um número cinco vezes maior que o contabilizado para a população rural. A cidade já enfrentava, na década de 70 , seu processo de urbanização, enquanto 0 estado de Alagoas apenas na década de 90 teve esse mesmo processo efetivado. Este aumento da marcha migratória do campo para cidade não foi uniforme na região fumageira, ao contrário de Arapiraca, muitos municípios só tiveram esse grande aumento na população urbana décadas depois, e o mesmo não foi suficiente para alcançar uma taxa de urbanização acima dos $50 \%$, ao final de 2010 , todos os municípios registraram uma população rural superior à população urbana, com exceção da cidade de Lagoa da Canoa.

No entanto, é importante frisar que houve também uma elevação significativa da população rural entre 1960 e 1970, sugerindo que ocorreu, aliado ao processo de urbanização, um aumento do número de nascidos vivos em toda região fumageira, pois tanto a população urbana quanto a rural cresceram a taxas elevadas neste período.

Parte dessa crescente taxa de urbanização em Arapiraca também pode ser explicada pela migração de pessoas dos municípios vizinhos, devido à visível concentração de emprego e renda na zona urbana da referida cidade, como será comprovado mais adiante. As novas relações de trabalho estabelecidas no campo, como citado anteriormente, criaram um grupo de trabalhadores rurais que não possuíam nenhum tipo de propriedade, por isso, não eram fixados ao campo e 
podiam migrar mais facilmente para a região que lhes proporcionassem mais oportunidades.

Corrêa (1992) analisa o crescimento urbano de Arapiraca entre 1970 e 1980, juntamente com os municípios de Palmeira dos Índios e Santana do Ipanema, que se destacavam na época como centros populacionais emergentes do interior de Alagoas. Ainda para o mesmo autor, tal crescimento populacional não foi devido apenas à vinda de excedentes do campo, mas também a uma ampliação quantitativa e qualitativa das funções destas cidades.

Funções essas que levaram Palmeira dos Índios e Santana do Ipanema a exercer forte influência nas mesorregiões Agreste e Sertão, respectivamente, e Arapiraca a tornar-se o centro da importante área fumageira que comanda.

Além disso, pode-se explicar que este expressivo aumento populacional urbano, entre 1950 e 1970, em Arapiraca, deveu-se à elevação significativa da produção fumageira aliada a grande feira que o município já detinha naquela época, que proporcionou o crescimento econômico necessário àquela cidade, como demonstrado no Gráfico 1 abaixo.

Gráfico 1. Produção de fumo em toneladas na região fumageira alagoana - 1950 a 1970.

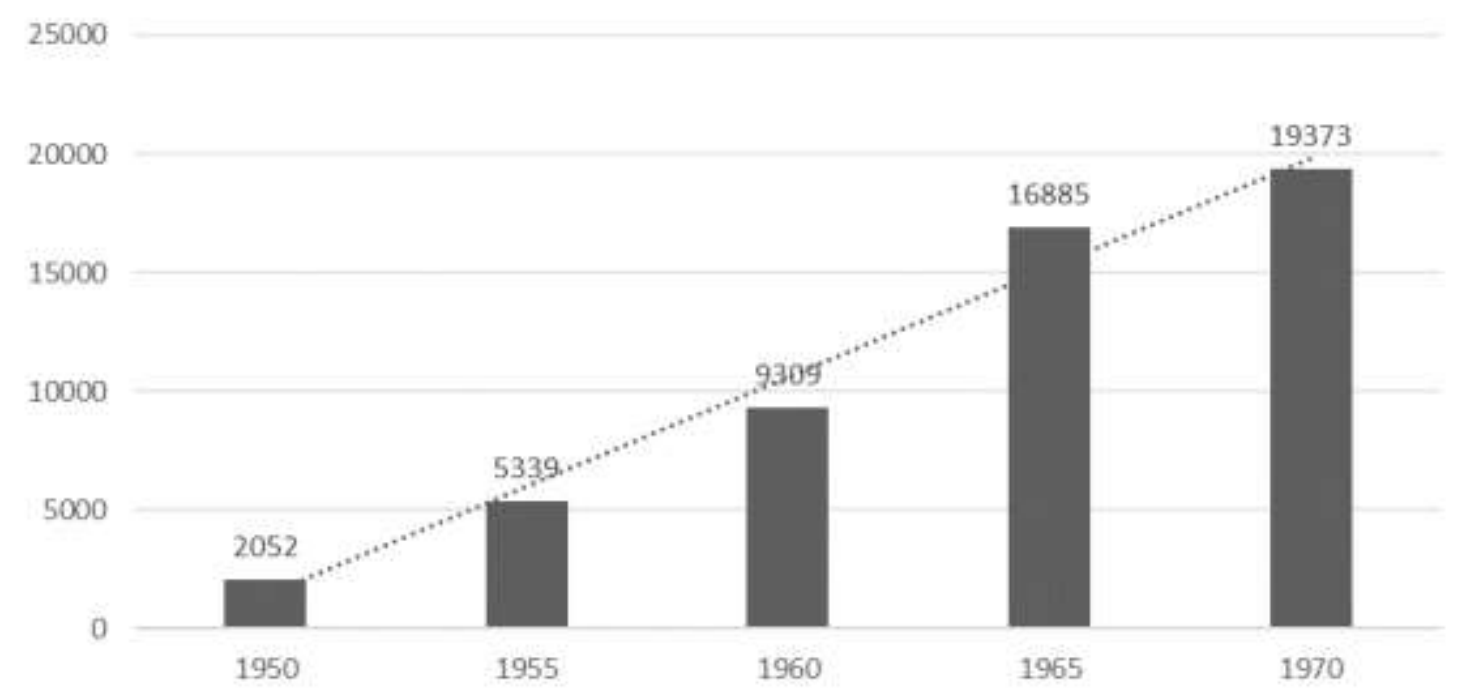

Fonte: Elaboração própria a partir do IPEADATA (2018).

Nota-se que a produção fumageira cresceu de forma expressiva entre 1950 e 1970 , mais precisamente $844 \%$. Neste período diversas empresas se instalaram nesta região, porém de forma muito concentrada no município de Arapiraca, como já dito anteriormente. O município foi o principal receptor da migração proveniente do aumento produtivo e dinâmico da cultura fumageira, pois o mesmo detinha grande 
parcela da produção desta cultura, como comprovado a partir da análise da Tabela 4.

Tabela 4. Produção do fumo em toneladas na região fumageira de Alagoas entre 1975 a 2010.

\begin{tabular}{l|cccccccc}
\hline \multicolumn{1}{c|}{ Município } & $\mathbf{1 9 7 5}$ & $\mathbf{1 9 8 0}$ & $\mathbf{1 9 8 5}$ & $\mathbf{1 9 9 0}$ & $\mathbf{1 9 9 5}$ & $\mathbf{2 0 0 0}$ & $\mathbf{2 0 0 5}$ & $\mathbf{2 0 1 0}$ \\
\hline Arapiraca & 11.234 & 13.883 & 11.650 & 14.400 & 8.000 & 4.800 & 5.760 & 5.115 \\
Campo Grande & - & 3 & 2 & 80 & 94 & 72 & 81 & 45 \\
Coité do Nóia & 97 & 1.376 & 1.800 & 2.400 & 1.800 & 840 & 300 & 314 \\
Craíbas & - & - & 2.000 & 1.946 & 2.400 & 2.100 & 600 & 2.655 \\
Feira Grande & 741 & 2.125 & 2.600 & 1.800 & 960 & 816 & 330 & 1.884 \\
Girau do Ponciano & 936 & 3.570 & 6.500 & 5.962 & 5.000 & 4.300 & 1.710 & 1.920 \\
Lagoa da Canoa & 3.529 & 1.640 & 2.100 & 2.160 & 1.920 & 960 & 480 & 2.934 \\
Limoeiro de Anadia & 126 & 2.322 & 1.500 & 120 & 180 & 200 & 230 & 186 \\
São Sebastião & 390 & 348 & 662 & 717 & 877 & 644 & 578 & 442 \\
Taquarana & 190 & 843 & 550 & 360 & 320 & 168 & 120 & 128 \\
\hline
\end{tabular}

Fonte: Elaboração própria a partir do IPEADATA (2018).

Em 1975, Arapiraca concentrava 65\% da produção de fumo da região, e manteve sua expressividade até 2010, como maior produtor. "A concentração produtiva associada à das técnicas e da racionalidade das empresas fumageiras no município de Arapiraca, proporcionou ao mesmo tempo uma concentração populacional e de serviços no referido município, evidências do desigual desenvolvimento do capital." (TEODORO, 2014, p.113)

A crescente urbanização, a partir de 1970, faz surgir no município cada vez mais atividades voltadas ao comércio e ao setor de serviços, e assim como a produção fumageira e a urbanização, a evolução do setor comercial também foi muito concentrada em Arapiraca, conforme Tabela 5.

Tabela 5. Evolução do comércio da região fumageira alagoana entre 1970 a 1995.

\begin{tabular}{l|ccccc}
\hline \multirow{2}{*}{ Município } & \multicolumn{5}{c}{ Número de Estabelecimentos } \\
\cline { 2 - 6 } & $\mathbf{1 9 7 0}$ & $\mathbf{1 9 7 5}$ & $\mathbf{1 9 8 0}$ & $\mathbf{1 9 8 5}$ & $\mathbf{1 9 9 5}$ \\
\hline Arapiraca & 635 & 888 & 556 & 747 & 1619 \\
Campo Grande & 21 & 34 & 1 & 22 & 14 \\
Coité do Nóia & 10 & 32 & 4 & 5 & 18 \\
Craíbas & & & & 34 & 20 \\
Feira Grande & 21 & 77 & 8 & 27 & 30 \\
Girau do Ponciano & 38 & 82 & 19 & 23 & 62 \\
Lagoa da Canoa & 37 & 32 & 13 & 44 & 15 \\
Limoeiro de Anadia & 31 & 45 & 5 & 7 & 35 \\
São Sebastião & 20 & 23 & 6 & 22 & 75 \\
Taquarana & 42 & 62 & 14 & 24 & 38 \\
\hline
\end{tabular}

Fonte: Elaboração própria a partir do IPEADATA (2018).

Em 1980, auge produtivo da cultura do fumo, 88\% dos estabelecimentos comerciais de todos os dez municípios da região fumageira estavam em Arapiraca. 
Apesar do ano em questão apresentar uma visível redução geral no número de estabelecimentos quando comparado ao ano de 1975, alguns municípios como Taquarana, por exemplo, fecharam 48 estabelecimentos de um total de 62. No entanto, no período de declínio produtivo fumageiro, a partir de 1985, o número de estabelecimentos mais que dobrou em Arapiraca, passando a registrar 1.619, em 1995. Mostrando o comércio como alternativa a crise fumageira que culminou naquele ano.

A visível queda no número de estabelecimentos de comércio entre 1975 e 1980 pode ser explicada por OLIVEIRA (2007), que relata uma crise de superprodução diante de uma tendência estrutural de redução de demanda do tabaco como era consumido e produzido pela região. Naquele ano, o comércio nascente ainda dependia do desempenho produtivo do fumo, que movimentava a economia local com seu grande fluxo de vendedores e compradores.

No que abrange o setor de serviços, a mesma tendência entre os anos de 1975 e 1980 ocorreu, queda expressiva no número de estabelecimentos, segundo demonstrado na Tabela 6. O reflexo da primeira crise de superprodução foi sentido de forma igualitária entre o setor de comércio e serviços e impactou de forma mais efetiva os municípios que não detinham a centralidade produtiva e comercial, ou seja, todos os municípios da região fumageira, com exceção de Arapiraca, que tiveram seu número de estabelecimentos reduzidos em mais de $70 \%$.

No município de São Sebastião, aproximadamente 99\% das empresas prestadoras de serviços fecharam as portas entre 1975 e 1980. Já a cidade de Arapiraca registrou uma queda de $41 \%$ no número de estabelecimentos. Entre os anos de 1970 e 1975 a produção fumageira caiu 10\%, fato que pode ter desestimulado o mercado, já que o desempenho produtivo desta cultura vinha desde 1945 registrando altas expressivas.

Tabela 6. Evolução dos serviços da região fumageira alagoana entre 1970 a 1995.

\begin{tabular}{l|ccccc}
\hline \multirow{2}{*}{ Municípios } & \multicolumn{5}{c}{ Número de Estabelecimentos } \\
\cline { 2 - 6 } & $\mathbf{1 9 7 0}$ & $\mathbf{1 9 7 5}$ & $\mathbf{1 9 8 0}$ & $\mathbf{1 9 8 5}$ & $\mathbf{1 9 9 5}$ \\
\hline Arapiraca & 363 & 421 & 245 & 395 & 221 \\
Campo Grande & 11 & 14 & 1 & 7 & 6 \\
Coité do Nóia & 2 & 2 & & 6 & 1 \\
Craíbas & & & & 6 & 1 \\
Feira Grande & 6 & 26 & 1 & 14 & 8 \\
Girau do Ponciano & 9 & 10 & 3 & 20 & 1 \\
Lagoa da Canoa & 6 & 6 & & 2 & 12 \\
Limoeiro de Anadia & 4 & 2 & & 19 & 6 \\
São Sebastião & 6 & 46 & 1 & 13 & 4 \\
Taquarana & 16 & 10 & 1 & & \\
\hline
\end{tabular}


Fonte: Elaboração própria a partir do IPEADATA (2018).

\section{Considerações Finais}

Portanto, tendo em vista as informações apresentadas neste estudo, concluímos que a dinâmica econômica, fruto do desenvolvimento produtivo fumageiro, mostrou-se muito mais concentrada no município de Arapiraca em detrimento das demais cidades da região fumageira. Embora, a região como um todo, tenha desfrutado dos auges produtivos do fumo, fica claro a dominação do referido município. Além disso, ficou comprovado o aumento da dinâmica social através no número de empregos e estabelecimentos que surgiram no agreste alagoano, e de forma mais concentrada em Arapiraca, evidenciando a capacidade produtiva da cultura em distribuir renda e impulsionar a economia local.

Como consequência, alterou-se a organização socioespacial do município, principalmente a partir de 1950 com a vinda das primeiras grandes empresas de exportação do fumo. Estas que ajudaram a promover o acelerado processo de urbanização da região, que entre 1960 e 1970, registrou elevação de 145\% em sua população urbana. A migração da população dos municípios vizinhos, reflexo, principalmente, da concentração de emprego e renda na zona urbana da referida cidade, pode ser a explicação para este aumento expressivo, visto que a mesma era estimulada a se deslocar em busca de emprego, sobretudo no período de elevação da produção do fumo. Cabe ressaltar que neste mesmo período a população rural também apresentou crescimento expressivo, não só em Arapiraca, mas nos demais municípios da região fumageira, ficando claro, desta forma, que houve um aumento geral do nível populacional para toda região entre 1960 e 1970. Já em 1980, o crescimento da população rural se apresenta em um ritmo muito menor quando comparado ao desenvolvimento populacional registrado nas zonas urbanas, principalmente no município de Arapiraca, que apresenta uma variação percentual de $87,2 \%$ entre os anos de 1970 e 1980.

No auge da produção fumageira em Arapiraca, por volta de 1990, o número de estabelecimentos comerciais mais que duplicou em comparação a 1985, mostrando a clara relação entre a evolução produtiva dessa cultura com a dinamização populacional e comercial da região, uma vez que, pelo comércio ser, naturalmente, grande gerador de empregos, o município apresentou uma ascenção populacional em 74\% entre 1980 e 2000, tanto pelo próprio crescimento natural da sua população quanto pelo processo migratório verificado no período em questão. 
Portanto, pode-se afirmar que o cultivo do fumo e sua futura ascensão foi fator primordial e determinante para o processo de urbanização atrelado diretamente ao desenvolvimento comercial local, que já era latente com a forte presença de feiras locais, e só cresceu a partir da dinamização social e econômica que ali surgiu.

\section{REFERÊNCIAS}

ANDRADE, M. C. A terra e o homem no Nordeste. 2.ed. São Paulo: Brasiliense, 1963.

ARAÚJO, A. M.; PAUFERRO, J. R. Organização e desenvolvimento territorial da atividade agrícola em Alagoas. XIX Encontro Nacional De Geografia Agrária, pp. 1-26. São Paulo, 2009.

CORRÊA, R. L. A Vida Urbana em Alagoas: A importância dos meios de transporte na sua evolução. In: Geografia, espaço e memória. São Paulo: Terra Livre, $n^{\circ} 10$, p.93-116, 1992.

FERRARIO, F. Da esperança a crise - a experiência das políticas regionais no Nordeste. Dissertação - Instituto de Economia - Universidade Estadual de Campinas, 2001.

FURTADO, C. Introdução ao desenvolvimento - enfoque histórico estrutural. $3^{a}$ ed. São Paulo. Paz e Terra, 2000.

INSTITUTO BRASILEIRO DE GEOGRAFIA E ESTATístICA (IBGE). Censo agropecuário 1970. Rio de Janeiro: IBGE.

INSTITUTO BRASILEIRO DE GEOGRAFIA E ESTATÍ́sTICA (IBGE). Censo agropecuário 1975. Rio de Janeiro: IBGE.

INSTITUTO BRASILEIRO DE GEOGRAFIA E ESTATÍ́STICA (IBGE) Censo agropecuário 1980. Rio de Janeiro: IBGE.

INSTITUTO DE PESQUISA ECONÔMICA APLICADA (IPEA). Ipeadata. Disponível em: <http://http://www.ipeadata.gov.br/?>. Acesso em: 28 out 2018.

OLIVEIRA, J.L. Da crise do setor fumageiro a diversificação produtiva em Arapiraca - al: projeto cinturão verde. Dissertação - Centro de Geografia e Desenvolvimento e Meio Ambiente, Universidade Federal de Alagoas, 2007.

SECRETARIA DE DESENVOLVIMENTO TERRITORIAL. Plano Territorial de Desenvolvimento Rural Sustentável do Agreste de Alagoas. Governo Federal, 2011.

SOUZA, J. C.; MARISCO, L. M.. Reestruturação urbana e a dinâmica socioeconômica em cidades médias: o caso de Arapiraca, Alagoas. Caderno Prudentino de Geografia, №31, vol.1, 2009.

TEODORO, A. P. S.. A reestruturação do território da região fumageira de alagoas. $230 \mathrm{f}$. Dissertação - Centro de Ciências Humanas, Letras e Arte, Universidade Federal do Rio Grande do Norte, 2014. 


\section{NOTAS DE AUTOR}

\section{CONTRIBUIÇÃO DE AUTORIA}

Maria Isabel Souza - Concepção. Coleta de dados. Análise de dados. Elaboração do manuscrito. Participação ativa da discussão dos resultados. Revisão e aprovação da versão final do trabalho.

Keuler Hissa Teixeira - Concepção. Coleta de dados. Elaboração do manuscrito. Participação ativa da discussão dos resultados. Revisão e aprovação da versão final do trabalho.

\section{FINANCIAMENTO}

Não se aplica.

\section{CONSENTIMENTO DE USO DE IMAGEM}

Não se aplica.

APROVAÇÃO DE COMITÊ DE ÉTICA EM PESQUISA

Não se aplica.

\section{CONFLITO DE INTERESSES}

Não se aplica.

\section{LICENÇA DE USO}

Este artigo está licenciado sob a Licença Creative Commons CC-BY. Com essa licença você pode compartilhar, adaptar, criar para qualquer fim, desde que atribua a autoria da obra.

\section{HISTÓRICO}

Recebido em: 03-03-2019

Aprovado em: 11-11-2019 